\title{
The effect of steam sterilization on different 3D printable materials for surgical use in veterinary medicine
}

\author{
Philipp Dautzenberg ${ }^{1 *} \mathbb{D}$, Holger A. Volk' ${ }^{1}$ Nikolaus Huels ${ }^{1}$, Lena Cieciora ${ }^{1}$, Katharina Dohmen ${ }^{1}$, Matthias Lüpke², \\ Herman Seifert ${ }^{2}$ and Oliver Harms ${ }^{1}$
}

\begin{abstract}
Background: Different 3D-printed materials polyactic acid (PLA), polyamide (PA), polycarbonates $(P C)$, acrylonitrile butadiene styrene (ABS) and GreenTEC Pro ${ }^{\circledR 1}$ have been considered for surgical templates, but there is a sparity of data about how these materials are affected by steam sterilization. The aim of the current study was to test if and how these materials change morphologically when high temperature, pressure and humidity are applied during the steam sterilization process. The overall aim is to create patient-specific sawing templates for performing corrective osteotomies. After the designing process, test-specimens with five different materials: PLA, PC, ABS, PA and GreenTEC Pro ${ }^{\circledR}$ were 3D-printed in two filling grades (30 and 100\%). The FDM method was used for printing. After 3D-printing, the test-specimens were steam sterilized with a standard program lasting $20 \mathrm{~min}$, at a temperature of $121^{\circ} \mathrm{C}$ and a pressure of 2-3 bar. In order to measure the deviation of the printed model, we measured the individual test-specimens before and after steam sterilization using a sliding gauge.

Results: PC, PA and ABS showed great morphological deviations from the template after 3D-printing and steam sterilization (>1\%) respectively. ABS proved unsuitable for steam sterilization. PLA and GreenTEC Pro ${ }^{\circledR}$ demonstrated fewer morphological deviations both before and after sterilization. Therefore, we decided to perform a second test just with PLA and Green-TEC Pro ${ }^{\circledR}$ to find out which material has the highest stability and is probably able to be used for clinical application. The smallest deviations were found with the GreenTEC Pro ${ }^{\circledR}$ solid body. After autoclaving, the specimens showed a deviation from the planned body and remained below the $1 \%$ limit.
\end{abstract}

Conclusion: Steam sterilization causes morphological deviations in 3D printed objects. GreenTEC Pro ${ }^{\circledR}$ seems to be a suitable material for clinical use, not only for intraoperative use, but also for precise modeling. Microbiological examination, as well as biomechanical tests, should be performed to further assess whether intraoperative use is possible.

\section{Background}

3D-printing is a rising technology in the field of personalized medicine becoming more readily available and affordable. In veterinary medicine, 3D-printing is also becoming more popular and gaining in importance [1].

\footnotetext{
*Correspondence: philipp.dautzenberg@tiho-hannover.de

1 Department of Small Animal Medicine and Surgery, University

of Veterinary Medicine Hannover, Bünteweg 9, 30559 Hannover, Germany

Full list of author information is available at the end of the article
}

Different printing techniques are described, the most common ones being Stereolitography (SLA), Fused Deposition Modeling (FDM), Selective Laser Sintering (SLS), Laminated Object Manufacturing (LOM) and PolyJet Technology [2]. To date, 3D-printing has been used in veterinary medicine in different fields, e.g. anatomical and surgical teaching, in veterinary orthopaedics, neurosurgery, oral and maxillofacial surgery [1]. Many techniques have been copied from human surgery.

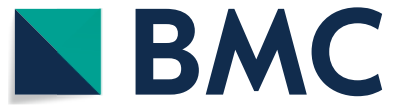

(C) The Author(s) 2021. Open Access This article is licensed under a Creative Commons Attribution 4.0 International License, which permits use, sharing, adaptation, distribution and reproduction in any medium or format, as long as you give appropriate credit to the original author(s) and the source, provide a link to the Creative Commons licence, and indicate if changes were made. The images or other third party material in this article are included in the article's Creative Commons licence, unless indicated otherwise in a credit line to the material. If material is not included in the article's Creative Commons licence and your intended use is not permitted by statutory regulation or exceeds the permitted use, you will need to obtain permission directly from the copyright holder. To view a copy of this licence, visit http://creativecommons.org/licenses/by/4.0/. The Creative Commons Public Domain Dedication waiver (http://creativeco mmons.org/publicdomain/zero/1.0/) applies to the data made available in this article, unless otherwise stated in a credit line to the data. 
3D printed templates or implants have been increasingly used in veterinary medicine. The material used varied and only small case numbers have been reported [3-11]. However, despite the promising reported surgical accuracy, very little is known how the material changes during printing and the steam sterilization process. Printability, mechanical properties, e.g., autoclavibility and robustness, biocompatibility and economic aspects are crucial when using $3 \mathrm{D}$ printing routinely in veterinary medicine [2].

Different studies in human medicine recommend to only use FDA-approved solution for 3D printing $[12,13]$. Shaheen et al. have tested the effect of steam sterilization and gas plasma sterilization on 3D printed materials in a pilot study and postulate that most FDM printed materials show greater morphological variations in steampressure sterilization and that gas plasma sterilization is the more suitable option [14]. Furthermore, they mention in their study that the sterilization of plastics is still relatively unexplored, although the field of 3D- printed metals has already been extensively studied in science.

In another study, steam sterilization had no effect on the 3D printed material [15]. Twenty-seven surgical templates were measured with an intraoral scanner before and after steam-heat sterilization. The surgical guides were produced with the help of an SLA printer and from the material Dental SG Resin. Both studies differed in the number of objects to be examined. Marei et al. claim that their study gives a better significance due to the larger number of objects to be examined. Török et al. also found no significant morphological changes after steam sterilisation. They investigated a polyjet photopolymer (Objet MED610) for its sterilisability and used different sterilisation methods for this purpose [16]. A summary of the studies mentioned can be found in Table 1 .

In the current study five different 3D printable materials polyactic acid (PLA), polyamide (PA, nylon), polycarbonates (PC), acrylonitrile butadiene styrene (ABS) and GreenTEC Pro ${ }^{\circledR}$ were tested for heat resistance to a standard steam sterilization technique to evaluate

Table 1 Summary of the already mentioned previously published studies: material, printing process and steam sterilization

\begin{tabular}{llll}
\hline studies & material & $\begin{array}{l}\text { 3D-printing- } \\
\text { method }\end{array}$ & steam sterilization \\
\hline $\begin{array}{l}\text { Marei et al. [15] } \\
\text { (MAREl et al. 2019) }\end{array}$ & Dental SG & SLA & possible \\
$\begin{array}{l}\text { Török et al. [16] } \\
\text { (TÖRÖK et al. 2020) }\end{array}$ & MED610 & Poly Jet & possible \\
$\begin{array}{l}\text { Shaheen et al. [14] } \\
\text { (SHAHEEN et al. 2018) }\end{array}$ & not stated & Poly Jet & not possible \\
\hline
\end{tabular}

whether these materials could be used clinically as surgical templates. The results of the study could provide a basis for the safe future use of 3D-printed templates in the various clinical settings.

\section{Results - morphological assessment Pre-test}

Our pre-test showed a lack of morphological properties of PC, PA and ABS in both filling levels. Moderate surface deformations were found on $\mathrm{PC}$, which were even more pronounced on ABS. The bodies have warped and could no longer be measured with a slide-gauge. After the autoclaving process, PA showed a change in the state of aggregation, the surface being slightly greasy and thus unsuitable for prompt intraoperative use.

If the test specimens already showed gross optical distortions, they were removed from the study for further tests.

Only PLA and GreenTEC Pro ${ }^{\circledR}$ showed dimensional stability suitable in our pre-tests for further investigations.

\section{Results of the dimensional stability tests of the materials Before autoclaving}

In the second run, five test specimens each in the filling grades 30 and $100 \%$ of the materials PLA and GreenTEC Pro ${ }^{\circledR}$ were printed $(n=20)$. The PLA with $30 \%$ filling showed the following results. After printing, the median deviation from the initial length was $+0.26 \%$, from the initial width $+0.65 \%$, from the initial depth $+3.1 \%$ and from the initial edge length - $1.1 \%$. For the PLA test specimens with a $30 \%$ filling, the median values of the length were $50.13 \mathrm{~mm}$, the width $40.27 \mathrm{~mm}$, the depth $10.31 \mathrm{~mm}$ and the edge length of the integrated square $9.89 \mathrm{~mm}$. After printing, PLA with a $100 \%$-filling showed a median percentage deviation from the initial length $+0.84 \%$, from the initial width $+1.63 \%$, from the initial depth $+8.1 \%$ and from the initial edge length - $4.7 \%$. For the PLA test specimens with a $100 \%$ filling, the median values of the length were $50.42 \mathrm{~mm}$, the width $40.62 \mathrm{~mm}$, the depth $10.80 \mathrm{~mm}$ and the edge length of the integrated square $9.51 \mathrm{~mm}$.

GreenTEC Pro ${ }^{\circledR}$ in the $30 \%$ fill showed a median deviation from the initial length $-0.18 \%$,

$+0.2 \%$ of the initial width, $+1.6 \%$ of the initial depth and $+0.1 \%$ of the initial edge length after printing. For the GreenTEC Pro ${ }^{\circledR}$ with a $30 \%$ filling, the median values were $49.85 \mathrm{~mm}$ in length, $40.05 \mathrm{~mm}$ in width, $10.17 \mathrm{~mm}$ in depth and $10.03 \mathrm{~mm}$ in the edge length of the integrated square. After printing, the GreenTEC Pro ${ }^{\circledR}$ solid showed a deviation from the initial length of $-0.12 \%$, from the initial width $+0.3 \%$, from the initial depth $+0.9 \%$ and from the initial edge length of the integrated square $-0.6 \%$. For 
the GreenTEC Pro ${ }^{\circledR}$ with $100 \%$ filling, the median values were $49.98 \mathrm{~mm}$ in length, $40.08 \mathrm{~mm}$ in width, $10.08 \mathrm{~mm}$ in depth and $9.96 \mathrm{~mm}$ in the edge length of the integrated square (Fig. 1).

\section{After autoclaving}

The length of the test specimen made of PLA material with a $30 \%$ filling was reduced by $-3.19 \%$ on average, the width by $-3.15 \%$ on average, the depth by $-0.58 \%$ on average and the edge length by $-0.30 \%$ on average. After autoclaving the PLA test specimens with a $30 \%$ filling, the median values of the length were $48.45 \mathrm{~mm}$, the width $38.98 \mathrm{~mm}$, the depth $10.20 \mathrm{~mm}$ and the edge length of the integrated square $9.88 \mathrm{~mm}$.

The length of the test specimen made of PLA material with a $100 \%$ filling was reduced by $-0.52 \%$ on average, the width by $-0.42 \%$ on average, the depth increased by $+0.83 \%$ on average and the edge length was reduced by

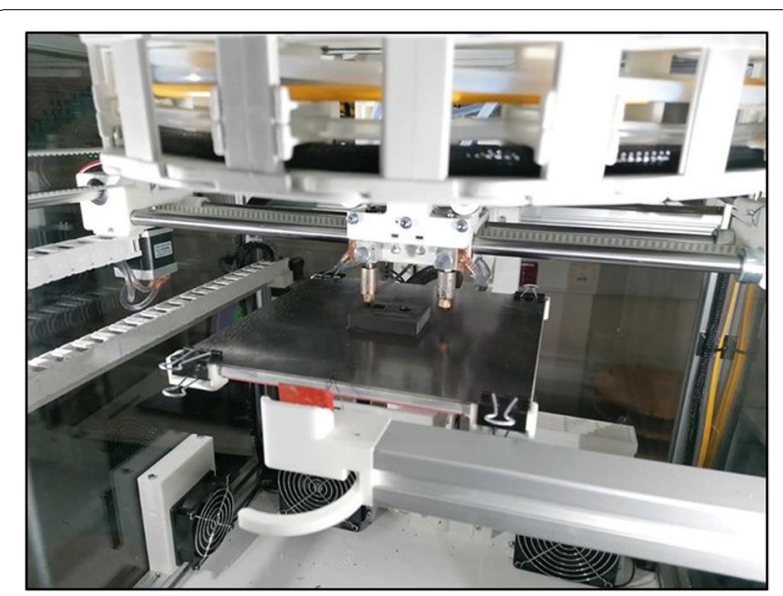

Fig. 1 Results in percent of morphological deviations of 3D printed test objects after printing process
- $0.84 \%$ on average. The body appeared to have become smaller in its entirety. After autoclaving, the PLA test specimens with a $100 \%$ filling showed median values in the length of $50.13 \mathrm{~mm}$, in the width of $40.48 \mathrm{~mm}$, in the depth of $10.89 \mathrm{~mm}$ and in the edge length of the integrated square of $9.44 \mathrm{~mm}$.

After autoclaving, GreenTEC Pro ${ }^{\circledR}$ in the $30 \%$ filling showed an average deviation of $-0.22 \%$ in length, $-0.12 \%$ in width, $+0.39 \%$ in depth and $-1.1 \%$ in the edge length of the square compared to the planned object. After autoclaving, the GreenTEC Pro ${ }^{\circledR}$ material in the $30 \%$ filling showed median values in the length of $49.74 \mathrm{~mm}$, in the width of $39.99 \mathrm{~mm}$, in the depth of $10.21 \mathrm{~mm}$ and in the edge length of the integrated square of $9.96 \mathrm{~mm}$. The test specimen with a $100 \%$ filling showed after autoclaving, the average deviation in length was - $0.1 \%$, in width $0.1 \%$, in depth $-0.1 \%$ and in the edge length of the square $-0.6 \%$.

After autoclaving, the specimens made of GreenTEC Pro ${ }^{\circledR}$ showed median values of $49.93 \mathrm{~mm}$ in length, $40.06 \mathrm{~mm}$ in width, $10.08 \mathrm{~mm}$ in depth and $9.91 \mathrm{~mm}$ in the edge length of the integrated square (Fig. 2).

The descriptive statistics can be seen in supplementary Table 3.

\section{Discussion}

In veterinary medicine, 3D printed implants are becoming increasingly important and affordable. Dogs have large breed specific variations in size and shape and 3D printing provides the ideal solution to adapt an implant to the individual patient. Due to the nature of 3D printed plastic materials, autoclaving is often an obstacle because the printed forms can quickly change morphologically. Finding a material that is biocompatible, robust, environmentally friendly and inexpensive poses even greater challenges for $3 \mathrm{D}$ printing. None of the $3 \mathrm{D}$ printed

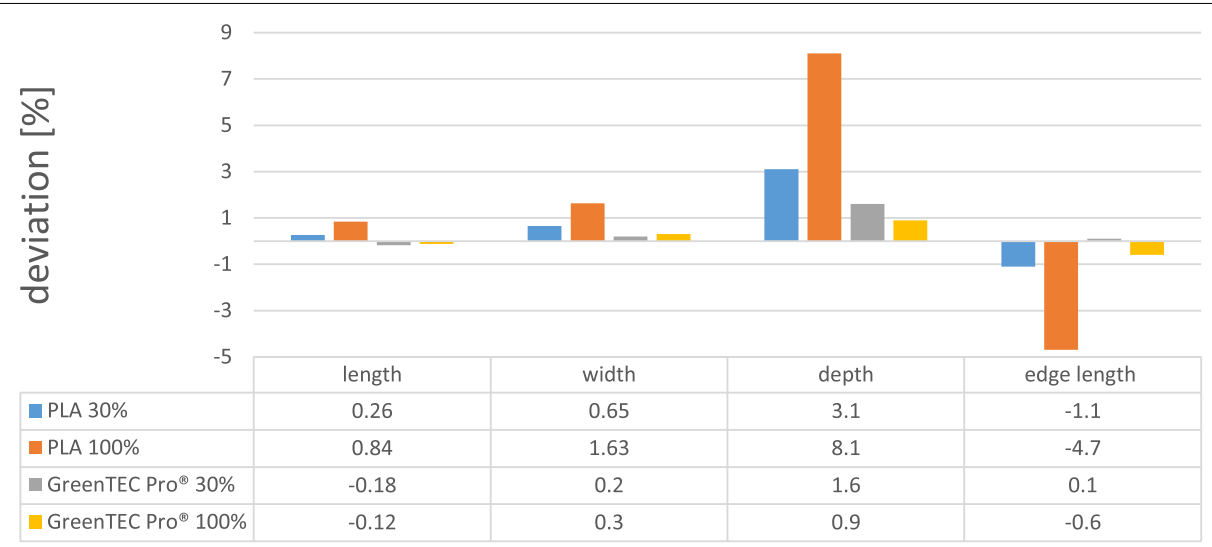

Fig. 2 Results in percent of morphological deviations of 3D printed test objects after sterilization 
material used in this study deviated less than $1 \%$ to the computer planned template, and should therefore not be seen as clinical useful according to Cone et al. [17]. The only material which deviated less than $1 \%$ in size after steam sterilization was GreenTEC Pro ${ }^{\circledR}$.

GreenTEC Pro ${ }^{\circledR}$ with a filling of $100 \%$ seems to be a suitable material for precise 3D modeling and because of its robustness after the autoclaving process may be appropriate for intraoperative use. GreenTEC Pro ${ }^{\circledR}$ is a high-performance biopolymer made from renewable raw materials and might therefore be the only material to be further considered for clinical use. The material is inexpensive, completely biodegradable and compostable. It is a medium-hard, but at the same time slightly flexible material that can withstand loads and possesses very good mechanical and thermal loading properties. Furthermore, the material is food safe and odourless [18].

GreenTEC Pro ${ }^{\circledR}$ fulfills the requirements of autoclavability, biocompatibility and economic aspects for clinical use. Robustness must be tested in a cadaver study to find out if an intraoperative use, e.g., as saw guide for corrective osteotomy surgery is possible.

The choice and number of different materials limits the study and further studies with larger case numbers should be investigated. The right print settings for the material are essential for a precise print result. These settings may differ in some cases from the manufacturer's specifications. Sometimes several test prints are necessary to achieve an accurate template. We tried various settings, but could still not get less than $1 \%$ deviations. Furthermore, different filling levels should also be tested in order to weigh up between robustness and material costs, as well as weight reduction.

In order to objectively assess the possible morphological deviations with high detail resolution, other technical devices, e.g., laser-technology or a micro CT examination before and after autoclaving are useful. Even small changes to the internal structure of the test body can be described and a computer-assisted measurement is feasible using this imaging technique.

\section{Conclusion}

$3 \mathrm{D}$ printing is gaining in importance in veterinary surgery, giving surgeons greater possibilities for an individualised patient solution. GreenTEC Pro ${ }^{\circledR}$ with a filling of $100 \%$ seems to be a suitable material for precise 3D modeling and because of its steam sterilization resistance may be appropriate for surgical use. Furthermore, it fulfills economic and ecological aspects that could facilitate its clinical use. Steam sterilization needs to be considered when developing new 3D printed surgical implants. Whether the material can be used as a surgical template for corrective osteotomies requires further microbiological and biomechanical investigations.

\section{Materials and methods \\ Design of the test bodies}

With the help of the software FreeCAD $0.18^{\text {II }}$, we designed a rectangular test body with an integrated square, which were used for measurements. The total edge lengths of the body were $50 \mathrm{~mm} \times 40 \mathrm{~mm} \times 10 \mathrm{~mm}$ with an edge length of the square being $10 \mathrm{~mm} \times 10 \mathrm{~mm}$.

\section{Materials}

In our study, we tested five different 3D printable materials: PLA, PA, PC, ABS and GreenTEC Pro ${ }^{\circledR}$. Each material was printed five times in two filling grades (30 and $100 \%)$.

Two test runs were performed. For the preliminary tests, two test specimens of each material were first printed. The first test specimen was made with a 30\% honeycomb-like filling, i.e. the space between the outer walls of the specimen was filled with thin walls forming a hexagonal pattern. The proportion of plastic in the interior was $30 \%$, while the remaining $70 \%$ was filled with air. The second test specimen was printed with a $100 \%$ plastic filling as a solid specimen. The test specimens in which the material already showed macroscopically recognisable deformations or changes in aggregate state after autoclaving were excluded for further investigations. The test bodies made of a material that appeared macroscopically stable after autoclaving were then printed again. Ten test specimens of each material were produced again, five of them with a $30 \%$ filling and five as solid specimens. Table 2 shows the material properties of GreenTEC Pro ${ }^{\circledR}$.

Table 2 Material Data Sheet GreenTEC Pro ${ }^{\circledR}$ [17]

\begin{tabular}{lll}
\hline Test & Method & Value/Unit \\
\hline Flexural modulus & ISO 527 & $4400 \mathrm{MPa}$ \\
Tensile strength & ISO 527 & $61 \mathrm{MPa}$ \\
Elongation at break & ISO 527 & $3,4 \%$ \\
Elongation at break & ISO 527 & $50 \mathrm{MPa}$ \\
Elongation at impact & ISO 527 & $3 \%$ \\
Notched impact strength & ISO $179-1 / 1 \mathrm{eA}$ & $4,4 \mathrm{kj} / \mathrm{m}^{2}$ \\
Impact resistance & ISO $179-171 \mathrm{eU}$ & $72 \mathrm{kj} / \mathrm{m}^{2}$ \\
Melt flow index (MFR) & ISO 1133 & $12 \mathrm{~g} / 10 \mathrm{~min}$ \\
Melting temperature & ISO $3146-\mathrm{C}$ & $190-210^{\circ} \mathrm{C}$ \\
VICAT A (VST) & ISO 306 & $160^{\circ} \mathrm{C}$ \\
Dimensional stability (HDT/B) & ISO 75 & $115^{\circ} \mathrm{C}$ \\
Shrinkage & ISO $294-4$ & $0,4 \%$ \\
Tightness & ISO 1183 & $1,39 \mathrm{~g} / \mathrm{cm}^{3}$ \\
\hline
\end{tabular}




\section{D printing process - FDM printing method}

The FDM method was used in the study. The principle of FDM is relatively simple. Filament plastic is heated and applied in layers to be processed on a heated plate. The process is protected by a chamber and cooled down so that the plastic can stiffen again [19]. Especially the setting of the first layer is important because this significantly influences the stability of the printed object. The first layer determines how successful the printing is.

In our study, we used the HT500 FDM printer III (Fig. 3).

\section{Steam sterilization}

Steam sterilization takes place in a pressure-resistant chamber, the so-called autoclave. Autoclaving can be divided into four steps. The first section is the climb time. During this time the interior of the autoclave is vented. During this process the atmospheric air is displaced from the interior and replaced by saturated, strained water vapour. The venting is carried out in a flow process or by fractional venting, after complete venting the venting valve is closed. After this time, the material to be sterilized also reaches the required temperature at any point by the action of saturated steam. Then the actual sterilization phase begins. The duration of the sterilization depends on the germ load and the sterilization temperature. After the sterilisation time, the cooling phase begins and thus the end of the autoclaving cycle. The reduction of postoperative complications is achieved by steam heat sterilization, as the microbial load is reduced, thus lowering the risk of infection [20,21]. Using a Selectomat $\mathrm{PL}^{\mathrm{IV}}$, for plastics, a standard program lasting $20 \mathrm{~min}$ is run at the Clinic for Small Animals, University of Veterinary Medicine Hannover, Hannover, Germany, at a temperature of $121^{\circ} \mathrm{C}$ and a pressure of $2-3 \mathrm{bar}$.

\section{Measurement}

To assess the accuracy of 3D printing and the subsequent autoclaving process, three investigators measured independently on three different days all twenty test specimens, including five 30\% filling PLA and GreenTEC Pro ${ }^{\circledR}$ and five $100 \%$ filling PLA and GreenTEC Pro ${ }^{\circledR}$ using a sliding gauge ( $\mathrm{n}$ per tester and material $=45$ ).

The measurements of the printed test specimens were compared with the data of the planned test specimen and the autoclaved test specimens with the printed specimens respectively. The percentage difference was determined and evaluated.

According to the publication of Cone et al., divergences above $1 \%$ are to be considered excessive and therefore unsuitable for clinical use [17].

\section{Statistical methods}

The statistical analysis was performed using the SAS Enterprise Guide 7.1 software. The measurement data of the printed test specimens were compared with the data of the planned test specimen and the autoclaved test specimens with the data of the printed test specimens. The percentage difference between the values was determined and statistically evaluated.

\section{Companies mentioned}

I) Copyright@ 2019 Extrudr |FD3D GmbH

II) Jürgen Riegel, Werner Mayer, Yorik van Havre, FreeCAD, Version 18.0, 2019

III) KühlingEKü̈hling GmbH, Christianspries 30, D-24159 Kiel, Germany

IV) MMM Group; Selectomat PL, Programm Kunststoff, 01004494571130; Serial-No.: EB090220, Sem-

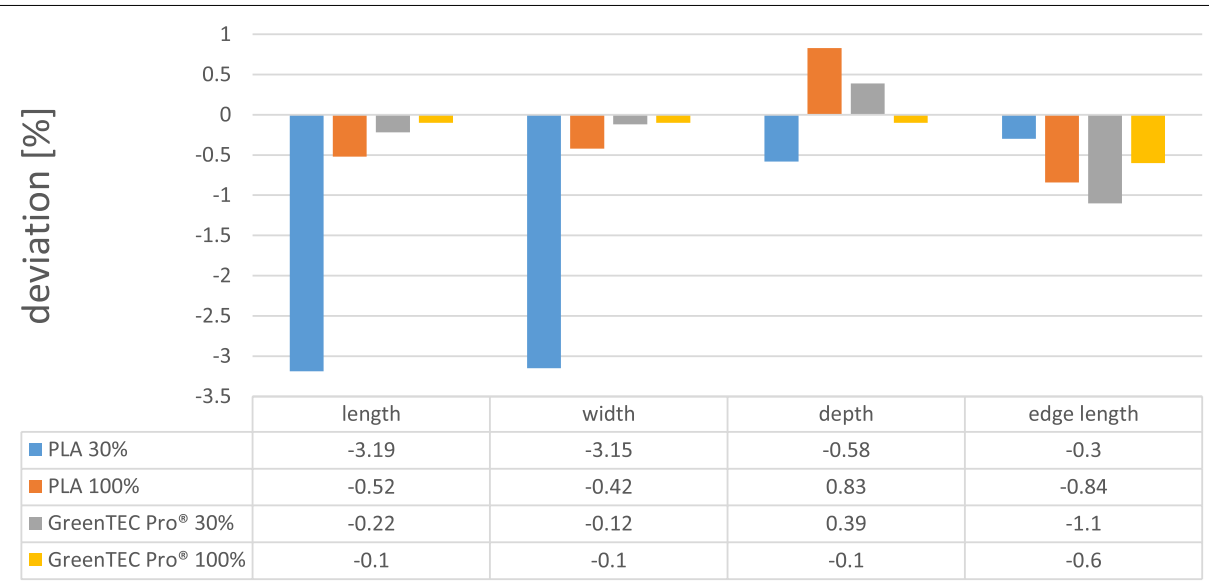

Fig. 3 FDM printing process of a test specimen made of the GreenTEC Pro ${ }^{\circledR}$ material 
melweisstraße 6, D-82152 Planegg/München, Germany

V) Connex ${ }^{\circledR}$, Conmetall Meister GmbH, Hafenstraße 26, D-29223 Celle, Germany

\section{Abbreviations}

3D: Three-dimensional; ABS: Acrylonitrile butadiene styrene; FDA: US Food and Drug Administration; FDM: Fused Deposition Modeling; PA: Polyamide; PC: Polycarbonates.

\section{Supplementary Information}

The online version contains supplementary material available at https://doi. org/10.1186/s12917-021-03065-8.

Additional file 1: Table 3. Representation of the median values and mean percentage deviations from the planned standard object. Representation of the materials PLA and GreenTEC Pro ${ }^{\circledR}$, in the filling degrees 30 and $100 \%$ ( $N=$ total number of measurements).

\section{Acknowledgments}

We wish to thank Frank Goblet, Steinbeis-Innovationszentrum Systemlösungen in Mess- und Automatisierungstechnik Mannheim, Germany and Dr. Jan Klasen for their excellent technical support.

\section{Authors' contributions}

$\mathrm{OH}$ conceived the presented idea. PD developed the theory and conducted the experiments. NH, LC and KD supported the measurements. ML provided technical support. PD drafted the manuscript and $\mathrm{HV}, \mathrm{HS}$ and $\mathrm{OH}$ critically read and edited the manuscript. HV and HS were involved in the data interpretation. All authors discussed the results and read the final manuscript. The authors read and approved the final manuscript.

\section{Funding}

This publication was financial supported by Deutsche Forschungsgemeinschaft and University of Veterinary Medicine Hannover, Foundation within the funding programme Open Access Publishing. The funders had no role in study design, data collection and analysis, decision to publish, or preparation of the manuscript.

\section{Availability of data and materials}

The datasets used and/or analysed during the current study are available from the corresponding author on reasonable request.

\section{Declarations}

Ethics approval and consent to participate Not applicable.

\section{Consent for publication}

Not applicable.

\section{Competing interests}

The authors declare that they have no competing interests.

\section{Author details}

${ }^{1}$ Department of Small Animal Medicine and Surgery, University of Veterinary Medicine Hannover, Bünteweg 9, 30559 Hannover, Germany. ${ }^{2}$ Department of General Radiology and Medical Physics, University of Veterinary Medicine Hanover, Bischofsholer Damm 15, 30173 Hannover, Germany.
References

1. Hespel AM, Wilhite R, Hudson J. Invited review--Applications for 3D printers in veterinary medicine. Vet Radiol Ultrasound. 2014;55(4):347-58.

2. Kalaskar DD. 3D printing in medicine. Woodhead publishing: Elsevier Ltd; 2017.

3. Huang $\mathrm{H}$, Hsieh MF, Zhang G, Ouyang H, Zeng C, Yan B, et al. Improved accuracy of 3D-printed navigational template during complicated tibial plateau fracture surgery. Australas Phys Eng Sci Med. 2015;38(1):109-17.

4. Worth AJ, Crosse KR, Kersley A. Computer-assisted surgery using 3D printed saw guides for acute correction of Antebrachial angular limb deformities in dogs. Vet Comp Orthop Traumatol. 2019;32(3):241-9.

5. Tack P, Victor J, Gemmel P, Annemans L. 3D-printing techniques in a medical setting: a systematic literature review. Biomed Eng Online. 2016;15(1):115.

6. Hall EL, Baines S, Bilmont A, Oxley B. Accuracy of patient-specific threedimensional-printed osteotomy and reduction guides for distal femoral osteotomy in dogs with medial patella luxation. Vet Surg. 2019:48(4):584-91.

7. Schweizer A, Mauler F, Vlachopoulos L, Nagy L, Fürnstahl P. Computerassisted 3-dimensional reconstructions of scaphoid fractures and nonunions with and without the use of patient-specific guides: early clinical outcomes and postoperative assessments of reconstruction accuracy. J Hand Surg Am. 2016;41(1):59-69.

8. Hafez MA, Chelule KL, Seedhom BB, Sherman KP. Computer-assisted total knee arthroplasty using patient-specific templating. Clin Orthop Relat Res. 2006;444:184-92.

9. Oka K, Murase T, Moritomo H, Goto A, Nakao R, Sugamoto K, et al. Accuracy of corrective osteotomy using a custom-designed device based on a novel computer simulation system. J Orthop Sci. 2011;16(1):85-92.

10. Ma B, Kunz M, Gammon B, Ellis RE, Pichora DR. A laboratory comparison of computer navigation and individualized guides for distal radius osteotomy. Int J Comput Assist Radiol Surg. 2014;9(4):713-24.

11. Oxley B. Bilateral shoulder arthrodesis in a Pekinese using three-dimensional printed patient-specific osteotomy and reduction guides. Vet Comp Orthop Traumatol. 2017:30(3):230-6.

12. Infection control recommendations for the dental office and the dental laboratory. ADA Council on scientific affairs and ADA Council on dental practice. J Am Dent Assoc. 1996;127(5):672-80.

13. Sennhenn-Kirchner S, Weustermann S, Mergeryan H, Jacobs HG, Borg-von Zepelin M, Kirchner B. Preoperative sterilization and disinfection of drill guide templates. Clin Oral Investig. 2008;12(2):179-87.

14. Shaheen E, Alhelwani A, Van De Casteele E, Politis C, Jacobs R. Evaluation of dimensional changes of 3D printed models after sterilization: a pilot study. Open Dent J. 2018:12:72-9.

15. Marei HF, Alshaia A, Alarifi S, Almasoud N, Abdelhady A. Effect of steam heat sterilization on the accuracy of 3D printed surgical guides. Implant Dent. 2019;28(4):372-7.

16. Török G, Gombocz P, Bognár E, Nagy P, Dinya E, Kispélyi B, et al. Effects of disinfection and sterilization on the dimensional changes and mechanical properties of 3D printed surgical guides for implant therapy-pilot study. BMC Oral Health. 2020;20(1):1-12.

17. Cone JA, Martin TM, Marcellin-Little DJ, Harrysson OLA, Griffith EH. Accuracy and repeatability of long-bone replicas of small animals fabricated by use of low-end and high-end commercial three-dimensional printers. Am J Vet Res. 2017:78(8):900-5.

18. FD3D G. Material Datenblatt, extrudr GreenTEC Pro. 25.06.2019.

19. Oswald MS, Hansmann ML. 3D approach visualizing cellular networks in human lymph nodes. Acta Histochem. 2018;120(8):720-7.

20. Omidkhoda M, Rashed R, Bagheri Z, Ghazvini K, Shafaee H. Comparison of three different sterilization and disinfection methods on orthodontic markers. J Orthod Sci. 2016;5(1):14-7.

21. Issa M, Abreu MJ, Schacher L, Adolphe D, Cabeco Silva ME. The influence of the sterilisation process on certain thermal properties. Eur J Appl Physiol. 2004:92(6):673-8.

\section{Publisher's Note}

Springer Nature remains neutral with regard to jurisdictional claims in published maps and institutional affiliations. 